\title{
Regulation of Murine Ovarian Epithelial Carcinoma by Vaccination against the Cytoplasmic Domain of Anti-Müllerian Hormone Receptor II
}

\author{
Cagri Sakalar, ${ }^{1,2}$ Suparna Mazumder, ${ }^{1}$ Justin M. Johnson, ${ }^{1,3}$ \\ Cengiz Z. Altuntas, ${ }^{1,4}$ Ritika Jaini, ${ }^{1}$ Robert Aguilar, ${ }^{1,3,5}$ \\ Sathyamangla V. Naga Prasad, ${ }^{6}$ Denise C. Connolly, ${ }^{7}$ and Vincent K. Tuohy ${ }^{1,3,8}$ \\ ${ }^{1}$ Department of Immunology, Lerner Research Institute, Cleveland Clinic, Cleveland, OH, USA \\ ${ }^{2}$ School of Medicine, Department of Medical Biology, Genome and Stem Cell Research Center, Erciyes University, 38039 Kayseri, Turkey \\ ${ }^{3}$ Department of Biology, Cleveland State University, Cleveland, OH, USA \\ ${ }^{4}$ North American University, Texas Institute of Biotechnology, Education, and Research, 10555 Stella Link Road, \\ No. 102, Houston, TX 77025, USA \\ ${ }^{5}$ Western Reserve Academy, Hudson, OH, USA \\ ${ }^{6}$ Department of Molecular Cardiology, Lerner Research Institute, Cleveland Clinic, Cleveland, OH, USA \\ ${ }^{7}$ Developmental Therapeutics Program, Fox Chase Cancer Center, Philadelphia, PA, USA \\ ${ }^{8}$ Department of Molecular Medicine, Cleveland Clinic Lerner College of Medicine, Case Western Reserve University, \\ Cleveland, OH, USA
}

Correspondence should be addressed to Vincent K. Tuohy; tuohyv@ccf.org

Received 16 July 2015; Accepted 12 October 2015

Academic Editor: Fabio Pastorino

Copyright (c) 2015 Cagri Sakalar et al. This is an open access article distributed under the Creative Commons Attribution License, which permits unrestricted use, distribution, and reproduction in any medium, provided the original work is properly cited.

\begin{abstract}
Anti-Müllerian hormone receptor, type II (AMHR2), is a differentiation protein expressed in 90\% of primary epithelial ovarian carcinomas (EOCs), the most deadly gynecologic malignancy. We propose that AMHR2 may serve as a useful target for vaccination against EOC. To this end, we generated the recombinant 399-amino acid cytoplasmic domain of mouse AMHR2 (AMHR2$\mathrm{CD}$ ) and tested its efficacy as a vaccine target in inhibiting growth of the ID8 transplantable EOC cell line in C57BL/6 mice and in preventing growth of autochthonous EOCs that occur spontaneously in transgenic mice. We found that AMHR2-CD immunization of C57BL/6 females induced a prominent antigen-specific proinflammatory CD4+ T cell response that resulted in a mild transient autoimmune oophoritis that resolved rapidly with no detectable lingering adverse effects on ovarian function. AMHR2-CD vaccination significantly inhibited ID8 tumor growth when administered either prophylactically or therapeutically, and protection against EOC growth was passively transferred into naive recipients with AMHR2-CD-primed CD4+ T cells but not with primed B cells. In addition, prophylactic AMHR2-CD vaccination of TgMISIIR-TAg transgenic mice significantly inhibited growth of autochthonous EOCs and provided a $41.7 \%$ increase in mean overall survival. We conclude that AMHR2-CD vaccination provides effective immunotherapy of EOC with relatively benign autoimmune complications.
\end{abstract}

\section{Introduction}

Epithelial ovarian cancer (EOC) is the leading cause of death from gynecologic malignancies in the United States [1,2]. Approximately $60 \%$ of ovarian cancers are diagnosed at late stages, and although initial responses to the current standard of care are high, most patients have disease recurrence resulting in a five-year overall survival (OS) rate slightly over $45 \%[2,3]$. The high rate of ovarian cancer recurrence and the low five-year survival rate indicate the urgency for more effective ways to control this disease.

Induction of ovarian tumor immunity through vaccination is a promising approach and finds support from the increased OS observed in patients whose ovarian tumors 
are infiltrated by $\mathrm{T}$ cells [4]. Several therapeutic ovarian cancer vaccine strategies have been employed using whole tumor homogenate strategies as well as approaches involving targeted immunity against tumor associated antigens (TAA) overexpressed in ovarian malignancies including human epidermal growth factor receptor 2 (HER2), cancer-testis antigen 1 (CTAG1B or NY-ESO-1), or cancer antigen 25 (CA-125) [5]. Thus far, targeted immunity against these non-ovarian-specific TAA has provided modest therapeutic results [6-8].

In contrast, vaccination against tissue-specific differentiation antigens has not been fully exploited for providing ovarian cancer therapy despite the ability of such targeted vaccinations to increase OS in melanoma and prostate cancer patients [9-11]. Thus, vaccination against differentiation proteins expressed at immunogenic levels predominantly in the tissue from which the tumor is derived may provide effective immunotherapy against established tumors and at the same time substantially lower risk of inducing systemic autoimmune inflammatory complications.

We selected mouse anti-Müllerian hormone receptor II (AMHR2, GenBank ID: 110542) as our target differentiation protein for ovarian cancer vaccination because its full-length expression in normal human tissues is confined to the ovary and because it is also expressed in the vast majority of human EOCs including $90 \%$ of primary EOCs, $78 \%$ of borderline malignancies, $77-86 \%$ of non-EOC ovarian tumors, and $56 \%$ of malignant ascites from grades III-IV ovarian cancers [1214].

AMHR2 is a serine/threonine kinase receptor homologous to type II receptors of the transforming growth factor beta (TGF $\beta$ ) family [15]. The human AMHR2 gene contains 11 exons with seven known alternatively spliced variants producing three known coded proteins, one additional variant with protein coding features, and three noncoding transcripts with no open reading frames $[16,17]$. In adult women, the longest human protein coding transcript for a 573-amino acid long protein is normally expressed only in the ovary and comprises a 127-amino acid extracellular domain, a 26-amino acid transmembrane domain, and a 403-amino acid cytoplasmic domain $[16,17]$. AMHR2 signaling causes regression of the Müllerian ducts during male development and regulates oocyte development and follicle production in adult females thereby providing substantial control of ovarian reserve and fertility [15, 18-20].

Based on its expression in $90 \%$ of primary human EOCs as well as on its relatively confined distribution in normal human tissues, we hypothesized that AMHR2 vaccination would provide effective immunotherapy against EOC without producing extensive autoimmune complications. We tested our hypothesis using both transplantable and autochthonous mouse models for EOC. Mouse ID8 cells, derived from repeated in vitro passage of mouse ovarian surface epithelial cells (MOSEC), form EOCs when inoculated into C57BL/6 mice [21]. TgMISIIR-TAg transgenic mice develop bilateral autochthonous EOCs due to expression of the simian virus 40 large T antigen (SV40-TAg) under control of the AMHR2 promoter [22].
All efforts to generate a full-length AMHR2 protein proved futile due to extensive toxicity in all expression systems tested. We resolved this toxicity problem by generating a recombinant mouse AMHR2 protein consisting of a 399-amino acid sequence of the cytoplasmic domain (AMHR2-CD) and found that immunization with this fragment resulted in a prominent proinflammatory $\mathrm{T}$ cell response accompanied by extremely high IgG antibody titers. Vaccination with AMHR2-CD provided highly significant $\mathrm{T}$ cell-mediated prophylaxis and therapy against ID8 EOC and mediated significant prophylaxis against the development of autochthonous EOCs in TgMISIIR-TAg transgenic mice. Moreover, the protection against tumor growth was accompanied by a rather benign autoimmune phenotype. Our data indicate that targeted vaccination against AMHR2-CD provides relatively safe and highly effective therapy against EOC.

\section{Materials and Methods}

2.1. Generation of Recombinant Mouse AMHR2-CD. mRNA was extracted from ovaries of 8-week-old female C57BL/6 mice. Primer pairs designed to amplify the AMHR2 sequence 170-568 were used to generate the entire 399-amino acid cytoplasmic domain of mouse AMHR2 by RT-PCR [23]. To optimize protein folding and enhance overall yield, substitutions for native codon sequences were made (Dapcel, Cleveland, $\mathrm{OH}$ ), and the optimized cDNA was inserted into the NdeI-Bam HI site of pET-3a (Novagen, Darmstadt, Germany) thereby providing a C-terminal 6xHis-tagged recombinant protein (Figure 1(a)). Plasmids containing these inserts were transformed in E. coli (Lucigen, Middleton, WI). High level expression colonies were selected following induction with Isopropyl $\beta$-D-1-thiogalactopyranoside (IPTG, Amresco, Solon, OH) and were sequenced for confirming proper orientation and alignment. The 6 xHis-tagged AMHR2-CD was purified under denaturing conditions using nickel-nitrilotriacetic acid (Ni-NTA) affinity chromatography (Qiagen Sciences, Germantown, MD). The purified AMHR2-CD was electrophoresed on denaturing SDS-PAGE gels (Bio-Rad, Hercules, CA) and blotted onto immunoblot PVDF membrane (Bio-Rad). Immune detection of AMHR2$\mathrm{CD}$ was performed using the enhanced chemiluminescence system (Amersham Biosciences, Piscataway, NJ) with HRPconjugated His antibody (Qiagen). Prior to use, the 6xHistagged AMHR2-CD was purified by reverse phase HPLC to yield endotoxin-free protein [24]. Levels of endotoxin were $<0.05$ endotoxin units $(<5 \mathrm{pg}$ ) per $\mathrm{mg}$ of recombinant protein.

2.2. Mice and Immunization. Female C57BL/6 mice served as recipients of ID8 tumors. They were obtained commercially (Jackson Laboratory, Bar Harbor, ME) at six weeks of age and immunized at 7-10 weeks of age by subcutaneous injection in the abdominal flanks with $100 \mu \mathrm{g}$ of recombinant mouse AMHR2-CD in $200 \mu \mathrm{L}$ of an emulsion of equal volumes of water and complete Freund's adjuvant (CFA, Difco, Detroit, MI) containing $400 \mu \mathrm{g}$ of Mycobacteria tuberculosis. TgMlSIIR-TAg (DR26 line) transgenic mice (provided by DDC) were maintained by breeding male TgMISIIR-TAg 


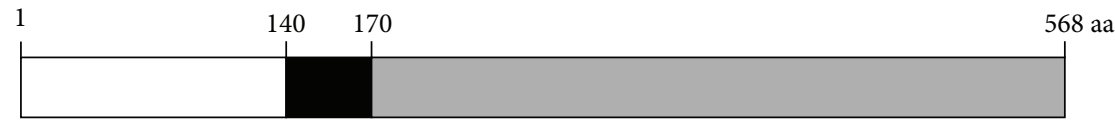

AMHR2
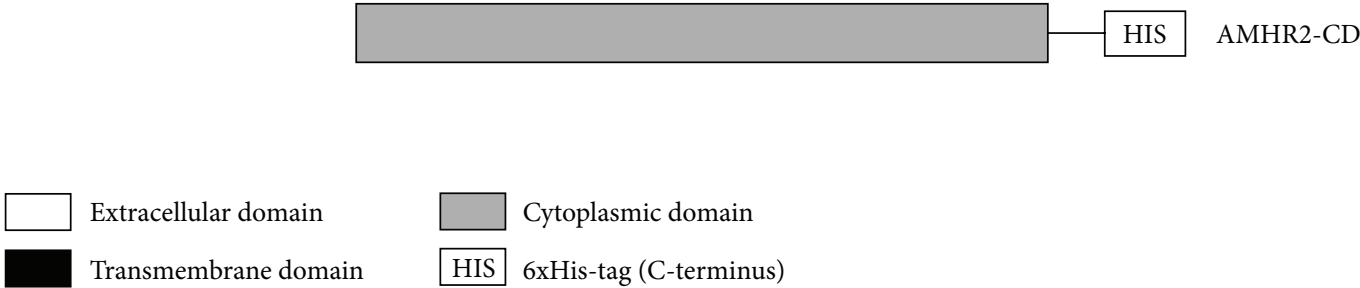

(a)

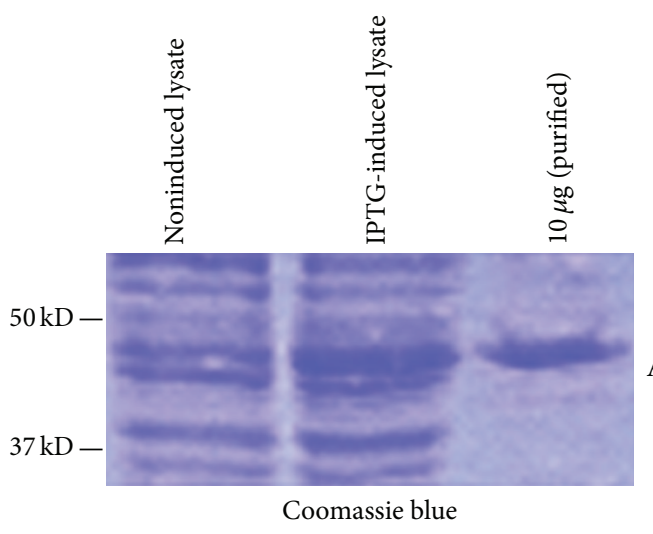

(b)

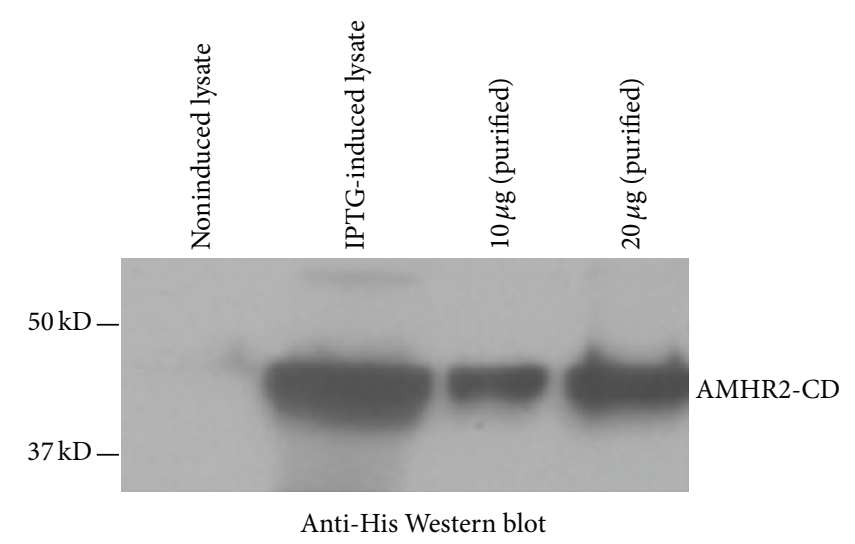

(c)

FIGURE 1: Generation of recombinant mouse AMHR2-CD. (a) Schematic representation of full-length AMHR2 showing the extracellular, transmembrane, and cytoplasmic domains with a C-terminal 6xHis-tagged AMHR2-CD variant. (b) Expression of AMHR2-CD in noninduced, IPTG-induced, and Ni-NTA affinity purified AMHR2-CD shown on an SDS-PAGE gel stained with Coomassie blue. (c) AntiHis Western blot of SDS-PAGE gel showing expression of AMHR2-CD in noninduced, IPTG-induced, and two doses of Ni-NTA affinity purified AMHR2-CD.

$\left(\mathrm{H}-2^{\mathrm{b}}\right)$ mice to wild-type syngeneic C57BL/6 females (Jackson Laboratory). TgMlSIIR-TAg mice were immunized at 6-7 weeks of age with $100 \mu \mathrm{g}$ of recombinant mouse AMHR2-CD in CFA as described above. To determine fertility phenotypes, age-matched test and control vaccinated C57BL/6 female mice were mated with the same $\mathrm{C} 57 \mathrm{BL} / 6$ males. All protocols were preapproved by Cleveland Clinic's Institutional Animal Care and Use Committee.

2.3. Tumor Inoculation and Measurement. The ID8 EOC cell line was generously provided by Dr. Kathy Roby (University of Kansas Medical Center, Kansas City, KS). ID8 cells were cultured in 75 or $225 \mathrm{~cm}^{2}$ tissue culture flasks (BD Biosciences, Franklin Lakes, NJ) in DMEM (Mediatech Cellgro, Manassas, VA) containing $4 \%$ fetal bovine serum (Thermo Scientific Hyclone, Logan, UT), $1 \%$ penicillin/streptomycin (Invitrogen, Carlsbad, CA), and insulin-transferrin-sodium selenite media supplement (Sigma-Aldrich, St. Louis, MO) until the cells became 70-80 \% confluent. Cells were harvested by trypsinization and washed twice with $\mathrm{PBS}$. Female C57BL/6 mice were inoculated subcutaneously in the left dorsal flank with $5 \times 10^{6}$ ID8 cells. Growth of ID8 tumors was assessed regularly by using a Vernier caliper to measure length $\times$ width. Tumor growth endpoint was determined by a measurement in any direction of $17 \mathrm{~mm}$.
2.4. In Vivo Imaging and Measurement of Autochthonous Ovarian Tumors. Bilateral ovarian tumor growth in female transgenic mice was measured monthly by ultrasound using the Vevo 770 high-resolution in vivo microimaging system for small animals (VisualSonics, Toronto, Canada). Real-time imaging of the abdomen was performed using the RMV704 low frequency probe/scan head and aqueous conductive gel after removing hair from the abdominal region. Anesthesia for immobilization was administered using a nose cone with continuous flow of $1-2 \% \mathrm{vol} / \mathrm{vol}$ isoflurane during the image acquisition period lasting less than 30 minutes, and oxygen supply was continuously maintained. The probe/scan head was moved over the abdominal area very gently after applying aqueous conductive gel. Measurements and calculation of tumor area were performed using the Vevo software BMode measurement tool allowing for a $2 \mathrm{D}$ assessment of ovarian tumor size in vivo with the polygon region of interest setting (VisualSonics). Measurement of solid tumor size by B-mode sonography has been shown to correlate well with histopathologic measurement [25].

2.5. RT-PCR. Tissues were excised and stored frozen in RNA-Later (Life Technologies, Grand Island, NY). RNA was extracted by tissue homogenization in TRIZOL reagent (Invitrogen), and cDNA was generated from bulk RNA using 
TABLE 1: Primer pairs used for cloning, qRT-PCR, detection of transgene, and conventional RT-PCR.

\begin{tabular}{|c|c|c|}
\hline Protein & Sequence $\left(5^{\prime}-3^{\prime}\right)$ & Amplicon length (bp) \\
\hline \multicolumn{3}{|c|}{ Cloning of AMHR2-CD } \\
\hline \multicolumn{3}{|c|}{ AMHR2-CD } \\
\hline Forward & GGATCCAAGGCCTGCAGAGTGCAAGGTG & \multirow{2}{*}{1209} \\
\hline Reverse & AAGCTTCTACTCATTTACATACACCTG & \\
\hline \multicolumn{3}{|c|}{ TgMISIIR-TAg transgene expression } \\
\hline \multicolumn{3}{|c|}{ SV40-TAg } \\
\hline Forward & TGCATGGTGTACAACATTCC & \multirow{2}{*}{773} \\
\hline Reverse & TTGGGACTGTGAATCAATGCC & \\
\hline \multicolumn{3}{|l|}{$q R T-P C R$} \\
\hline \multicolumn{3}{|l|}{ IFN $\gamma$} \\
\hline Forward & GGATATCTGGAGGAACTGGCAA & \multirow{2}{*}{110} \\
\hline Reverse & TGATGGCCTGATTGTCTTTCAA & \\
\hline \multicolumn{3}{|l|}{$\mathrm{TNF} \alpha$} \\
\hline Forward & CGAGTGACAAGCCTGTAGCC & \multirow{2}{*}{209} \\
\hline Reverse & GTGGGTGAGGAGCACGTAGT & \\
\hline \multicolumn{3}{|l|}{ IL-2 } \\
\hline Forward & GCAGGCCACAGAATTGAAAG & \multirow{2}{*}{207} \\
\hline Reverse & TCCACCACAGTTGCTGACTC & \\
\hline \multicolumn{3}{|l|}{ CD4 } \\
\hline Forward & ACACACCTGTGCAAGAAGCA & \multirow{2}{*}{69} \\
\hline Reverse & GCTCTTGTTGGTTGGGAATC & \\
\hline \multicolumn{3}{|l|}{ CD8 } \\
\hline Forward & TTACATCTGGGCACCCTTG & \multirow{2}{*}{132} \\
\hline Reverse & TTGCCTTCCTGTCTGACTAGC & \\
\hline \multicolumn{3}{|l|}{ NKR-P1A } \\
\hline Forward & GGCTTGGCATGAGTCACC & \multirow{2}{*}{75} \\
\hline Reverse & TTCAGAGCCAACCTGTGTGA & \\
\hline \multicolumn{3}{|l|}{$\beta$-actin } \\
\hline Forward & GGTCATCACTATTGGCAACG & \multirow{2}{*}{133} \\
\hline Reverse & ACGGATGTCAACGTCACACT & \\
\hline \multicolumn{3}{|c|}{ Conventional RT-PCR } \\
\hline \multicolumn{3}{|c|}{ AMHR2 } \\
\hline Forward & GTATCCGCTGCCTCTACAGC & \multirow{2}{*}{193} \\
\hline Reverse & CAGAAGTCAGTGCCACAGGA & \\
\hline \multicolumn{3}{|l|}{$\beta$-actin } \\
\hline Forward & GGTCATCACTATTGGCAACG & \multirow{2}{*}{133} \\
\hline Reverse & ACGGATGTCAACGTCACACT & \\
\hline
\end{tabular}

Superscript III (Invitrogen). Gene expression was quantified by qRT-PCR using SYBR Green PCR mix (Applied Biosystems, Carlsbad, CA) with gene-specific primers (Table 1). Relative gene expression was assessed by normalization of each test gene expression level to $\beta$-actin expression levels in each individual tissue. Gene expression was determined by conventional RT-PCR using AMHR2-specific and $\beta$-actinspecific primers (Table 1). After amplification through 30 cycles, PCR products were separated on agarose gels $(2 \%$ in $1 \mathrm{TBE}$ buffer) and visualized under ultraviolet light after staining with ethidium bromide. Transgene expression in offspring of TgMlSIIR-TAg mice was determined by PCR amplification of a $773 \mathrm{bp}$ fragment of SV40-TAg using primer pairs as previously described [22] (Table 1).
2.6. Flow Cytometry Analysis of Tumor Infiltrating Lymphocytes (TILs). TILs were isolated from ID8 tumors by digestion of minced tumor for 30 minutes at $37^{\circ} \mathrm{C}$ in HBSS containing $50 \mathrm{KU}$ of DNase I (Sigma-Aldrich) and $0.2 \mathrm{mg} / \mathrm{mL}$ collagenase II (Life Technologies) followed by discontinuous gradient centrifugation. The partially purified TILs were treated with $\mathrm{Fc} \gamma$ III/II receptor antibody (BD Biosciences) in PBS containing $0.5 \%$ BSA and $0.05 \%$ sodium azide and double-stained with FITC-conjugated anti-mouse CD3 and either PE-conjugated anti-mouse CD4 or PE-conjugated anti-mouse CD8 (BD Biosciences). The CD3+ T cell population was gated and analyzed for percentages of CD4+ and CD8+ T cells. Data collected on 30,000 total events were analyzed using FlowJo software (BD Biosciences). 
2.7. Passive Transfer of Tumor Immunity. Ten days after immunization of female C57BL/6 mice with AMHR2-CD or ovalbumin (OVA, Sigma-Aldrich) as an irrelevant control immunogen, LNCs at $5 \times 10^{6}$ cells $/ \mathrm{mL}$ were activated in vitro with $20 \mu \mathrm{g} / \mathrm{mL}$ of immunogen in the presence of IL$12(10 \mathrm{ng} / \mathrm{mL})$ and IL-18 (10 ng/mL; Peprotech, Rocky Hill, NJ) in 24-well flat-bottom Falcon plates (BD Biosciences) in a total volume of $2.0 \mathrm{~mL} /$ well in DMEM supplemented as described above. After 3 days of restimulation, $2 \times 10^{7}$ activated whole LNCs were injected intraperitoneally into sublethally.

$\gamma$-irradiated (5 Gy) naive female recipients. In another protocol, C57BL/6 female mice were immunized with either AMHR2-CD or OVA, and four weeks later, three groups of cells were injected intraperitoneally into sublethally $\gamma$ irradiated $(5 \mathrm{~Gy})$ naive female recipients including $7.5 \times$ $10^{7}$ whole splenocytes reactivated with immunogen, IL-12, and IL-18 as described above, $2 \times 10^{7}$ similarly reactivated $\mathrm{CD} 4+\mathrm{T}$ cells purified from whole splenocytes by magnetic bead separation, and $2 \times 10^{7}$ nonreactivated B220+ B cells also purified from whole splenocytes by magnetic bead separation. In all cases, hosts were inoculated subcutaneously on the day after cell transfer with $5 \times 10^{6}$ ID8 cells, and tumor growth was assessed regularly as described above. Purities of enriched cells were determined by flow cytometry analysis using CellQuest software (BD Biosciences) and were consistently found to be $>90 \%$.

2.8. Immunologic Assays. T cell proliferation, ELISA assays for cytokine production, and immunohistochemical analysis were performed as previously described [26] and are detailed in supplemental material.

2.9. Biostatistical Analysis. Differences between mRNA expression levels and mean tumor weights were compared using Student's $t$-test. Differences between tumor growth curves were compared by unweighted one-way ANOVA, and differences in mouse survival curves were compared using the log-rank test.

\section{Results}

3.1. Generation of Recombinant Mouse AMHR2-CD. All attempts to express the full-length sequence of mouse AMHR2 in any expression system consistently caused cytotoxicity and failure to produce high expression colonies. To overcome this persistent cytotoxic effect, we expressed the longest hydrophilic domain of mouse AMHR2 consisting of the 170-568 sequence comprising the 399 amino acids of the entire cytoplasmic domain (Figure 1(a)). The Ni-NTA affinity purified C-terminal 6xHis-tagged protein migrated as a $\sim 44 \mathrm{kD}$ protein as determined by Coomassie blue staining of an SDS-PAGE gel (Figure 1(b)) and by Western blot immunostaining using HRP-conjugated His-specific antibody (Figure 1(c)).

3.2. Immunogenicity of AMHR2-CD. Ten days after AMHR2CD immunization of female C57BL/6 mice, LNC showed proliferation in a dose response manner to AMHR2-CD but not to recombinant human cochlin, a control protein generated and purified in a manner similar to AMHR2-CD (Figure 2(a)) [27]. This antigen-specific proliferation by LNC was elicited from purified CD4+ T cells but not from purified CD8+ T cells (Figure 2(b)) and was inhibited by treatment of cultures with CD4-specific but not CD8-specific antibodies (Figure 2(c)). Four weeks after immunization, ELISA analysis of supernatants from immunogen-stimulated splenocytes showed a predominant proinflammatory response to AMHR2-CD with high production of interferon gamma $(\mathrm{IFN} \gamma)$ and with relatively low production of IL-2, IL-4, and IL-5 (Figure 2(d)). Purification of T cell subsets from the whole splenocyte population showed that CD4+ but not $\mathrm{CD} 8+\mathrm{T}$ cells produced the IFN $\gamma$ in response to AMHR2-CD (Figure 2(e)). Two months after immunization, serum levels of AMHR2-CD-specific IgG were detectable even at titers exceeding 1:50,000 dilution (Figure 2(f)).

\subsection{Benign Transient Ovarian Inflammation following} AMHR2-CD Immunization. We next examined the potential of AMHR2-CD immunization to induce ovarian autoimmunity. Four and eight weeks after AMHR2-CD immunization of C57BL/ 6 female mice, ovarian IFN $\gamma$ gene expression was measured by qRT-PCR. Relative ovarian IFN $\gamma$ gene expression was modestly elevated 4 weeks after AMHR2-CD immunization but not after immunization with CFA alone (Figure 3(a)). Eight weeks after immunization, relative ovarian IFN $\gamma$ gene expression was similar in both immunized groups of mice. Most notably, the transiently elevated IFN $\gamma$ gene expression observed in AMHR2-CD immunized mice at 4 weeks was only 3 -fold higher than CFA control mice, far lower than what we had previously observed in lactating breast tissues from mice immunized with $\alpha$-lactalbumin where the levels of IFN $\gamma$ gene expression were more than 50 times greater than those occurring in CFA immunized control mice and were associated with substantial breast inflammation and lactation failure [26]. Despite repeated attempts to detect $\mathrm{CD} 3+\mathrm{T}$ cells in ovaries by immunohistochemical analysis at 4,8 , and 12 weeks after AMHR2-CD immunization, we could not find any infiltrates. More importantly, the low level transient expression of IFN $\gamma$ in ovaries of AMHR2-CD immunized mice was not associated with any detectable effect on ovarian function determined by fertility over four sequential mating cycles during which no significant differences $(P>0.60)$ occurred in the number of pups generated per litter between AMHR2-CD and CFA immunized mice (Figure 3(b)). Moreover, it remains highly unlikely that AMHR2-CD immunization induces any substantial nonovarian autoimmune inflammation since we found that AMHR2 gene expression was readily detected in the ovaries and ID8 ovarian tumor cells and was not detected at any appreciable levels in normal mouse uterus, stomach, spleen, heart, lung, kidney, and liver (Figure 3(c)).

3.4. Inhibition of Tumor Growth in Mice Immunized with AMHR2-CD. We next determined whether vaccination with AMHR2-CD would inhibit growth of transplantable ID8 tumors in C57BL/6 female mice. We found that ID8 tumor 


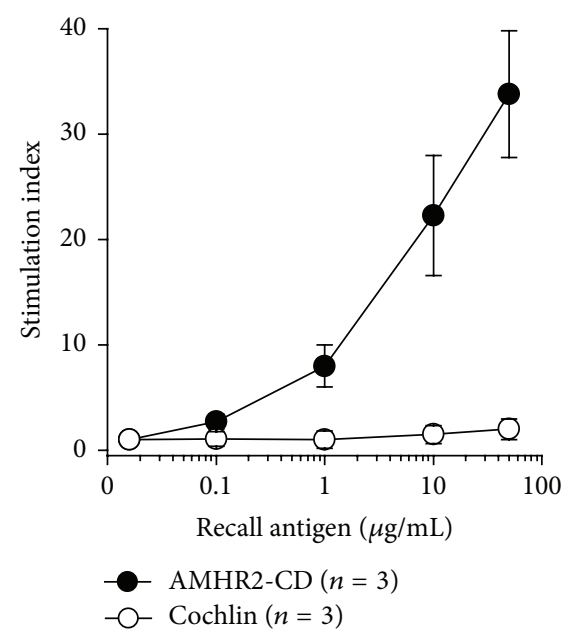

(a)

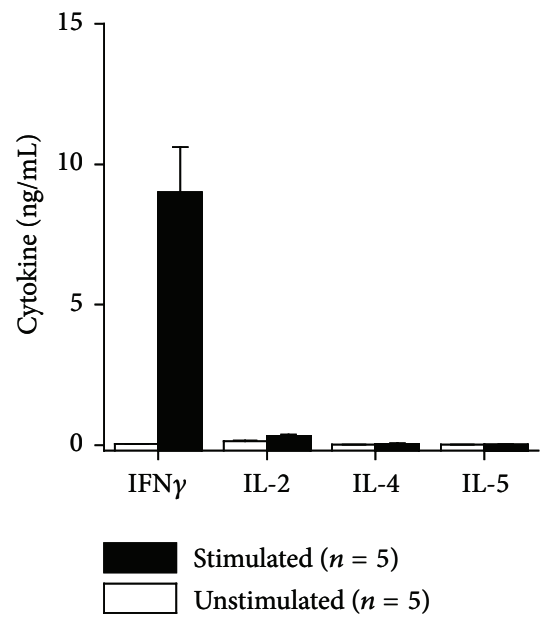

(d)

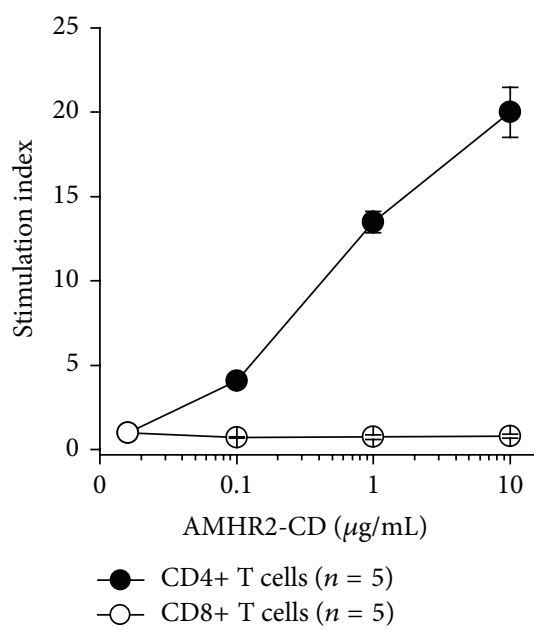

(b)

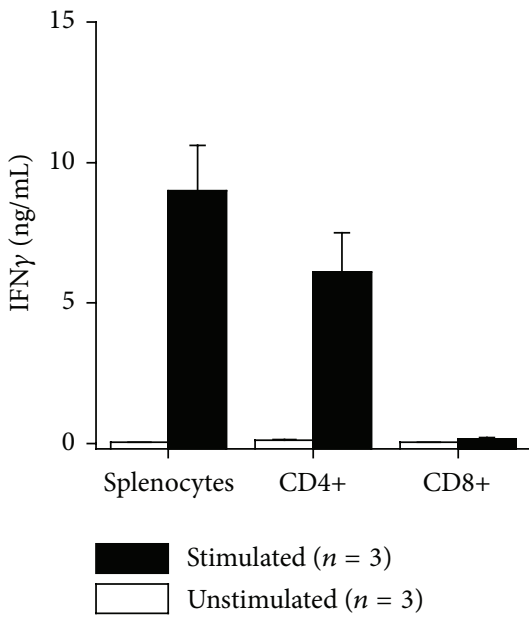

(e)

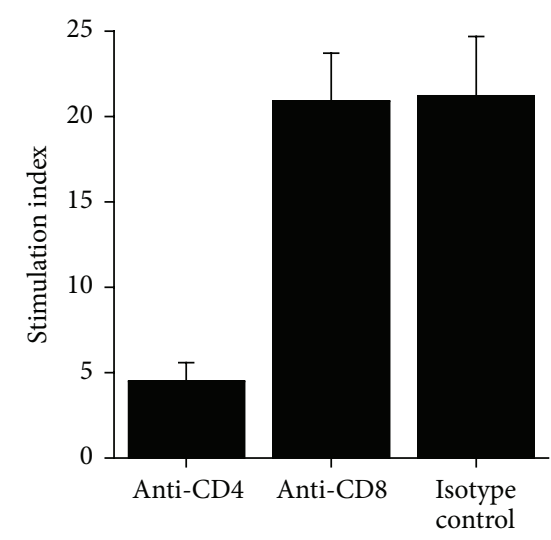

(c)

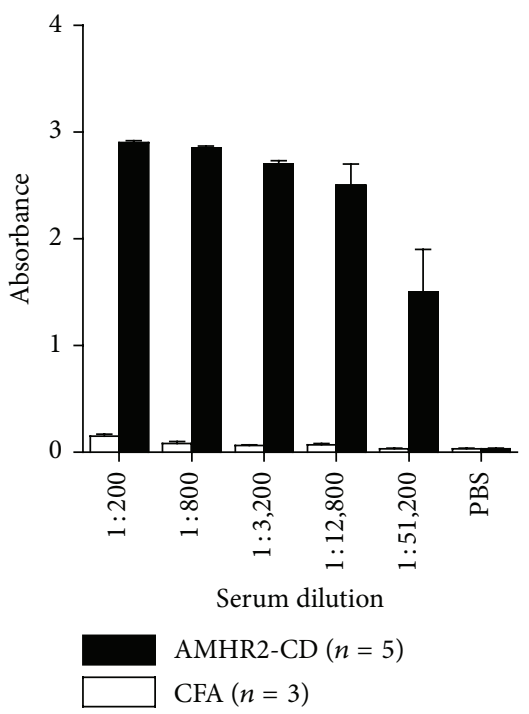

(f)

FiguRE 2: Immunogenicity of AMHR2-CD. Female C57BL/6 mice were immunized with AMHR2-CD in CFA, and LNC or splenocytes were cultured in vitro for assessment of proliferation and cytokine production. (a) Ten-day primed LNC showed marked antigen-specific recall proliferative responses to AMHR2-CD over several logs of antigen concentration. (b) The response to AMHR2-CD was elicited by CD4+ T cells but not by CD8+ T cells purified by magnetic bead separation. (c) Proliferative responses to AMHR2-CD were markedly inhibited in the presence of CD4 antibody but not in the presence of CD8 or isotype control antibodies. (d) Four weeks after immunization, splenocytes were reactivated with immunogen and ELISA analysis of 72-hour culture supernatants showed that recall responses to AMHR2-CD involved a proinflammatory phenotype with elevated production of IFN $\gamma$ and minimal production of IL-2, IL-4, and IL-5. (e) Splenocyte production of IFN $\gamma$ was elicited from purified CD4+ T cells but not from purified CD8+ T cells. (f) Two months after immunization, serum levels of AMHR2-CD-specific IgG were detectable even at titers over 1:50,000 dilution. PBS was substituted for diluted sera in the PBS control. Error bars show \pm SD.

growth was inhibited in mice prophylactically vaccinated 15 days (Figure $4(\mathrm{a}), P<0.001$ ), 7 days (Figure $4(\mathrm{~b}), P<0.001$ ), or 1 day (Figure $4(\mathrm{c}), P<0.05$ ) prior to inoculation of ID8 ovarian tumor cells. In addition, AMHR2-CD vaccination resulted in a significantly decreased overall tumor load as measured by final ID8 tumor weight at termination of experiments in mice vaccinated 7 days $(P<0.01)$ and 1 day $(P<0.05)$ prior to ID8 inoculation (Figure $4(\mathrm{~d}))$. AMHR2$\mathrm{CD}$ vaccination was also effective as therapy against EOC. Vaccination with AMHR2-CD 60 days after inoculation of ID8 tumors significantly inhibited the growth of established, palpable ID8 tumors $(P<0.05$, Figure $4(e))$. We also found that vaccination with AMHR2-CD significantly inhibited the growth of autochthonous EOCs that develop spontaneously in TgMlSIIR-TAg transgenic mice $(P<0.0001$, Figure $4(\mathrm{f}))$. Moreover, this inhibition in tumor growth was accompanied by a highly significant increased OS when compared to CFA vaccinated control mice $(P<0.0005$, Figure $4(\mathrm{~g}))$. This enhanced lifespan in AMHR2-CD vaccinated mice (mean 191.25 days \pm 22.95 ) compared to CFA vaccinated control mice (mean 135 days \pm 13.89 ) represents a dramatic $41.7 \%$ increase in OS. 


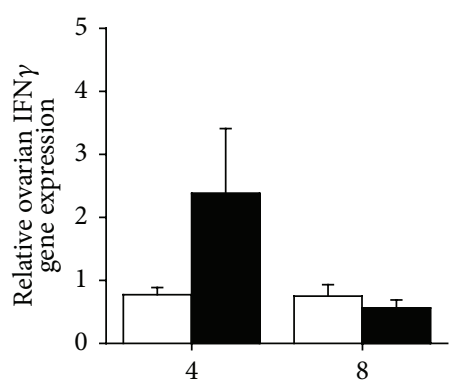

Week after immunization

AMHR2-CD $(n=5)$

CFA control $(n=4)$

(a)

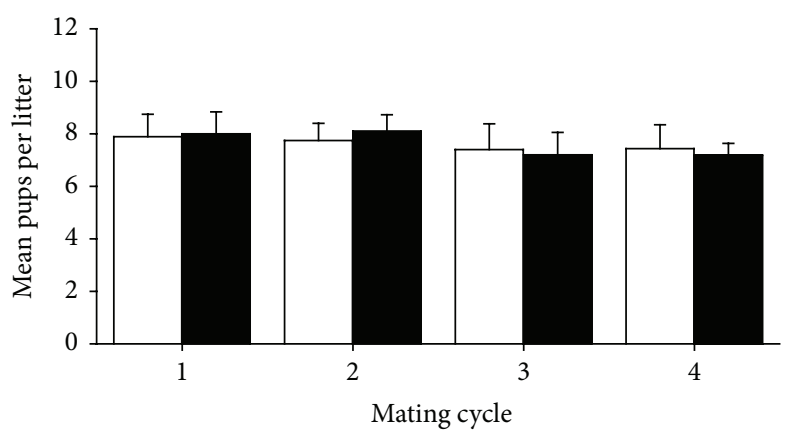

AMHR2-CD $(n=8)$

CFA control $(n=8)$

(b)
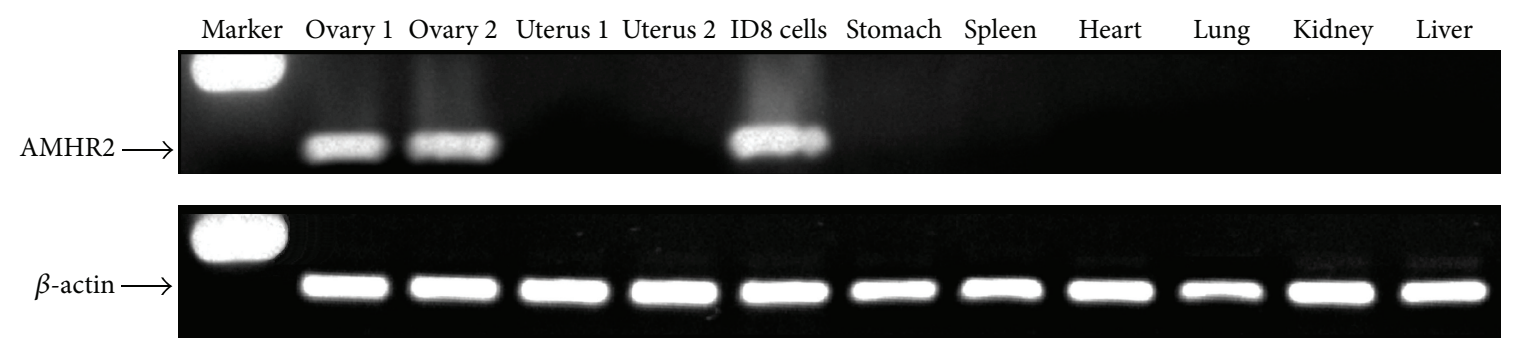

(c)

FIGURE 3: Benign transient ovarian inflammation following AMHR2-CD immunization. (a) Relative ovarian IFN $\gamma$ gene expression was elevated 4 weeks after immunization with AMHR2-CD but not after immunization with CFA alone. At eight weeks after immunization, relative ovarian IFN $\gamma$ gene expression was similar in both immunized groups of mice. (b) The low level transient expression of IFN $\gamma$ in ovaries of AMHR2CD immunized mice was not associated with any detectable effect on ovarian function as determined by assessing fertility defined by pup production over four sequential mating cycles in female C57BL/6 mice immunized with AMHR2-CD and control mice immunized with CFA alone. (c) AMHR2 gene expression was confined to ovaries and ID8 ovarian tumor cells and was not detected in normal uterus, stomach, spleen, heart, lung, kidney, and liver. Error bars show \pm SD.

3.5. ID8 Tumor Analysis. At the termination of experiments, tumors were analyzed for inflammatory infiltrates. Immunohistochemical analysis consistently showed extensive infiltration of CD3+ T cells in tumors from AMHR2-CD vaccinated mice (Figure 5(a)). We found no infiltrates in tumors from mice immunized with CFA alone (data not shown). Flow cytometry analysis of TILs showed a pronounced increase of CD4+ T cells in tumors from mice vaccinated with AMHR2CD compared to control mice immunized with CFA alone (40.7\% versus $11.7 \%$, Figure 5(b)). Substantial increases of CD8+ $\mathrm{T}$ cells in tumors did not occur in AMHR2-CD immunized mice compared to CFA immunized control mice (10.5\% versus $7.4 \%$, resp.). We next analyzed tumor RNA for gene expression of proinflammatory factors by qRT-PCR. When compared to tumors from CFA immunized control mice, tumors from AMHR2-CD immunized mice consistently showed significantly increased relative gene expression $(P<0.05$ in all cases) for CD4, IFN $\gamma$, tumor necrosis factor alpha (TNF $\alpha)$, IL-2, and the natural killer cell receptor NKRP1A [28] but not for CD8 (Figure 5(c)). These data indicate the induction of a proinflammatory immune milieu within the ID8 tumor following immunization with AMHR2-CD.

3.6. Passive Transfer of Tumor Immunity with CD4+ T Cells. All recipient mice were inoculated with ID8 tumor cells on the day after cell transfer. Tumor growth was significantly inhibited in mice transferred with AMHR2-CD-specific LNCs $(P=0.04$, Figure $6(\mathrm{a}))$ and splenocytes $(P<0.01$, Figure 6(b)) when compared to mice receiving OVA-specific LNCs. At 190 days after transfer of primed splenocytes and tumor inoculation, mean tumor weights were significantly lower in recipients of AMHR2-CD-specific splenocytes compared to recipients of OVA-specific splenocytes $(P<0.05$, Figure 6(c)). Transfer of AMHR2-CD-specific CD4+ T cells purified from 4-week primed splenocytes resulted in significant inhibition of ID8 tumor growth compared to transfer of purified OVA-specific CD4+ T cells $(P<0.0004$, Figure $6(d))$ whereas transfer of AMHR2-CD-primed B220+ B cells purified from 4-week primed splenocytes did not significantly inhibit ID8 tumor growth compared to transfer of OVAprimed B220+ B cells $(P=0.07$, Figure 6(d)). Thus, AMHR2CD-specific proinflammatory CD $4+\mathrm{T}$ cells are sufficient for transferring immune protection against the growth of EOC.

\section{Discussion}

Our data derived from both transplantable and autochthonous ovarian tumor models show that vaccination against AMHR2-CD, a defined fragment of an ovarian differentiation 


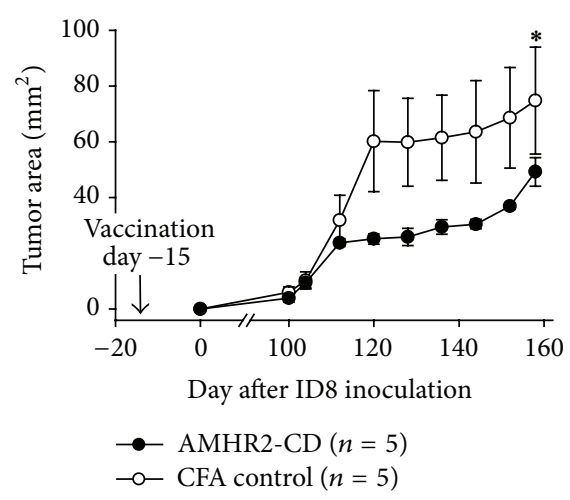

(a)

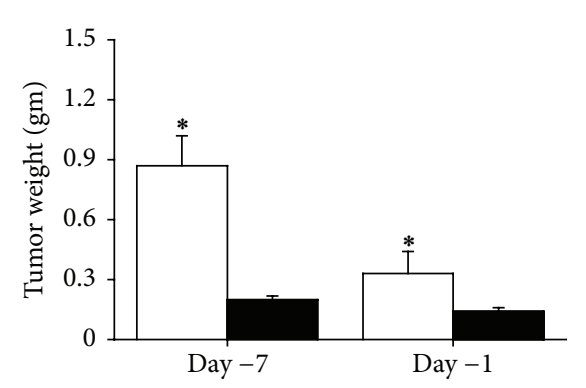

Day of vaccination

AMHR2-CD $(n=5)$

CFA control $(n=4)$

(d)

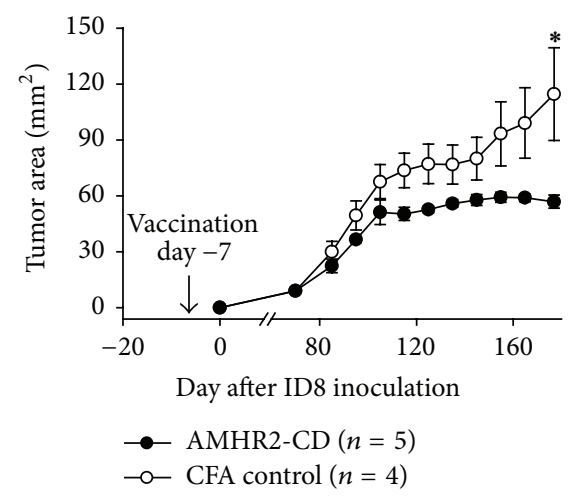

(b)

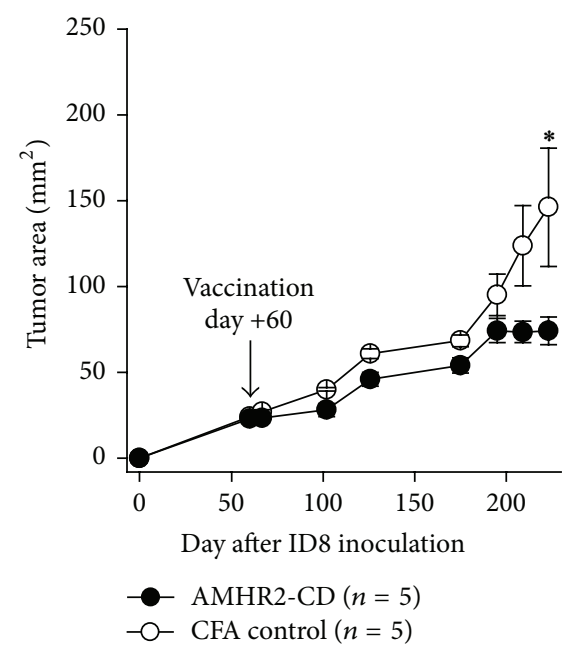

(e)

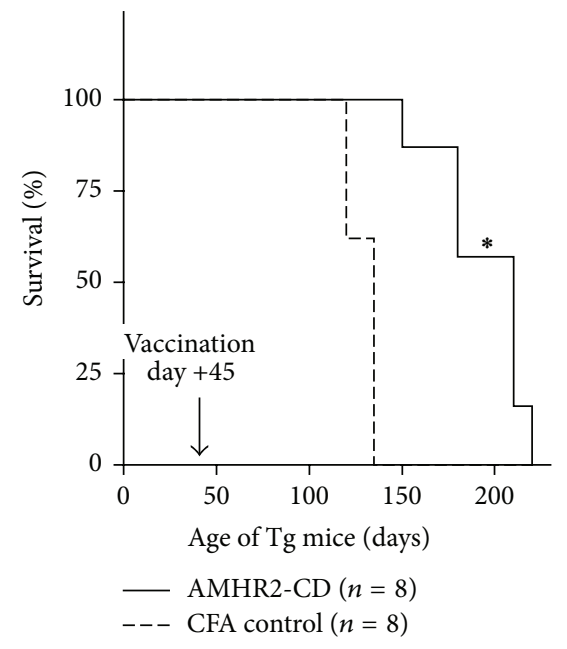

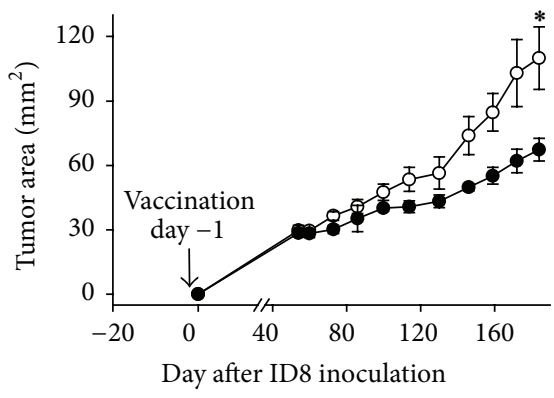

$\longrightarrow$ AMHR2-CD $(n=5)$

$-\infty$ CFA control $(n=4)$

(c)

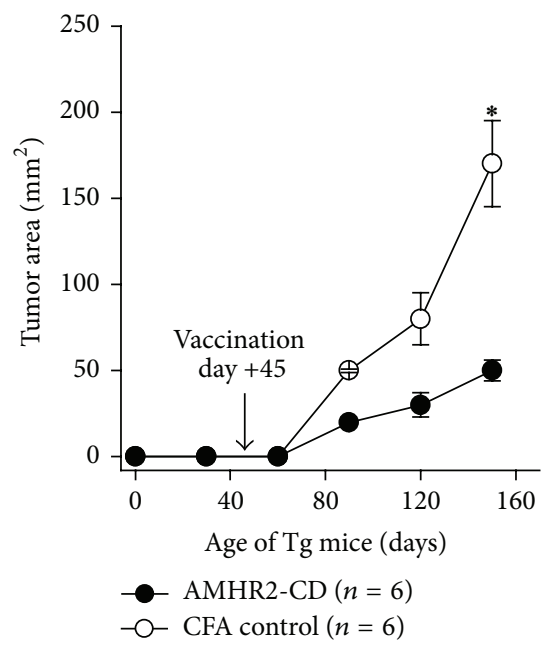

(f)

(g)

FIGURE 4: Inhibition of tumor growth in mice immunized with AMHR2-CD. ID8 tumor growth was inhibited in mice prophylactically vaccinated (a) 15 days, (b) 7 days, or (c) 1 day prior to inoculation of tumor cells. (d) AMHR2-CD vaccination resulted in a significantly decreased overall tumor load as measured by final tumor weight at termination of experiments in mice vaccinated 7 days and 1 day prior to ID8 inoculation. (e) Therapeutic vaccination with AMHR2-CD 60 days after inoculation of ID8 tumors significantly inhibited the growth of established, palpable, and growing ID8 tumors. (f) Prophylactic vaccination of female TgMlSIIR-TAg transgenic mice at 6-7 weeks of age with AMHR2-CD resulted in a highly significant inhibition in growth of autochthonous EOC. (g) Prophylactic AMHR2-CD vaccination of female TgMlSIIR-TAg transgenic mice at 6-7 weeks of age resulted in a highly significant $41.7 \%$ mean increased OS compared to control mice vaccinated with CFA alone. Asterisks indicate statistical significance. Error bars show \pm SD. 


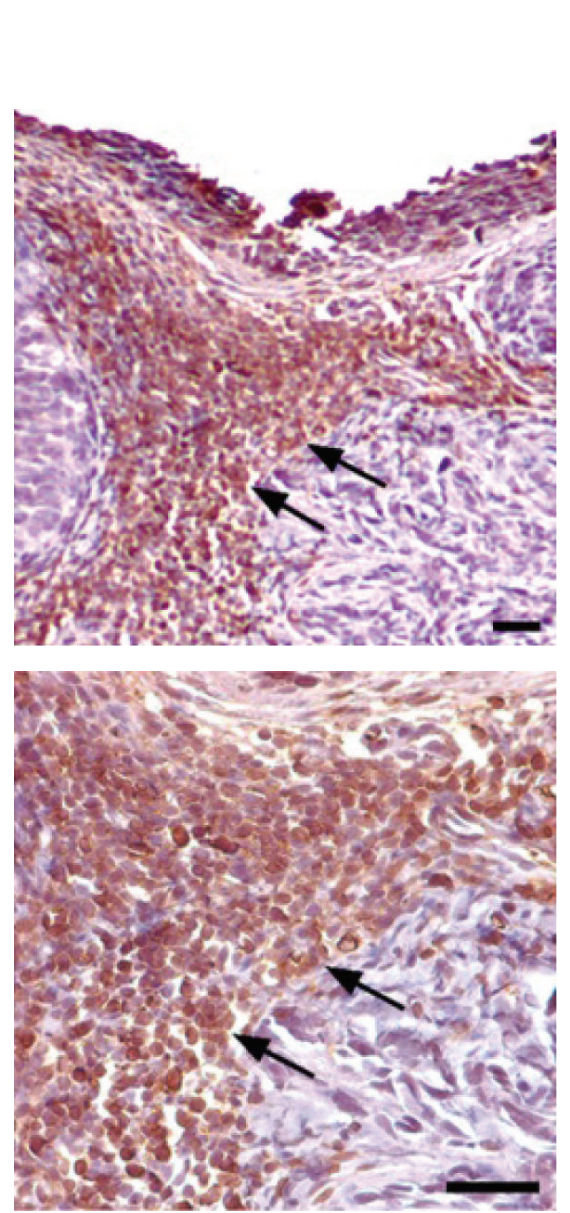

(a)
CFA
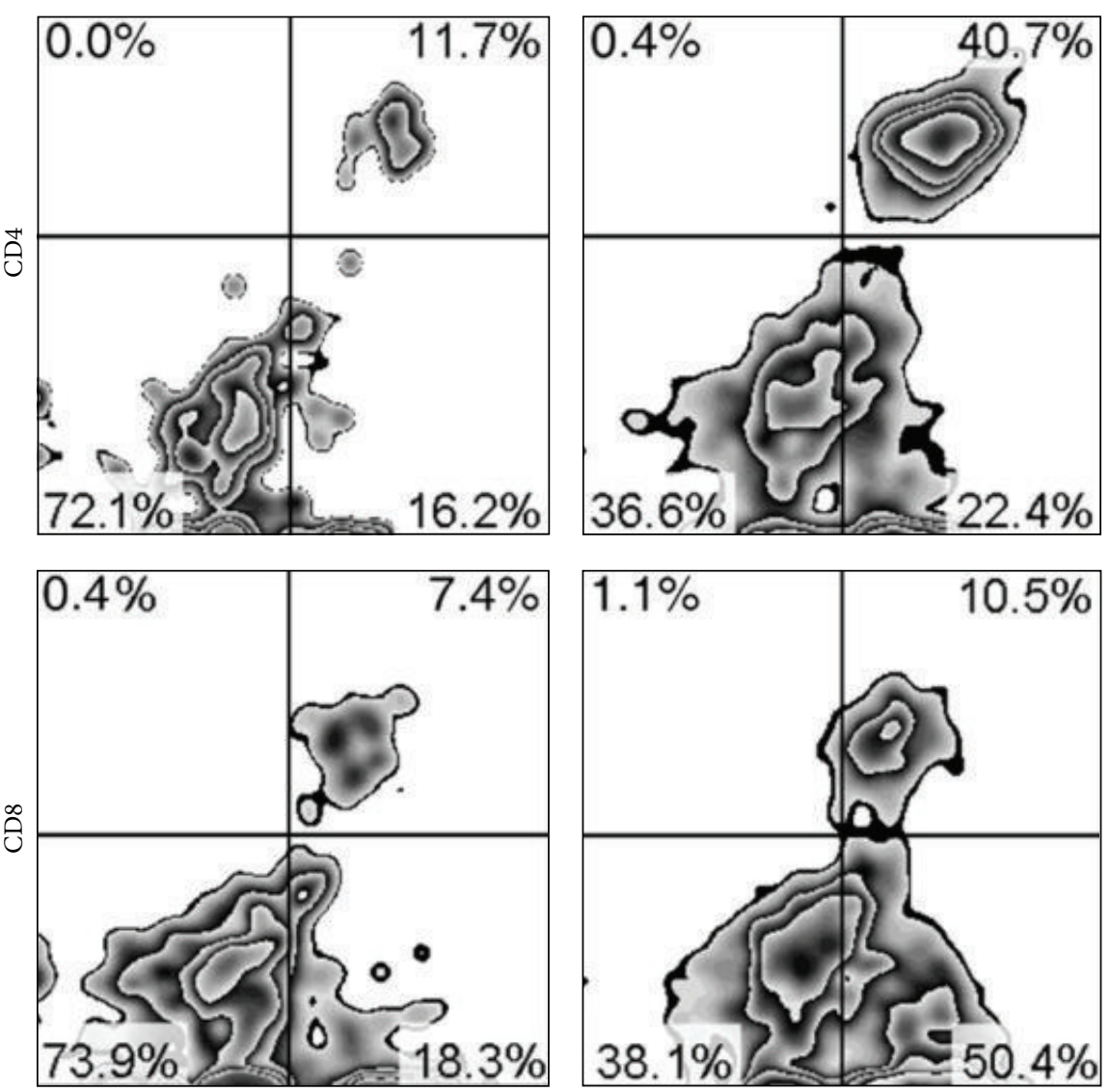

CD3

(b)

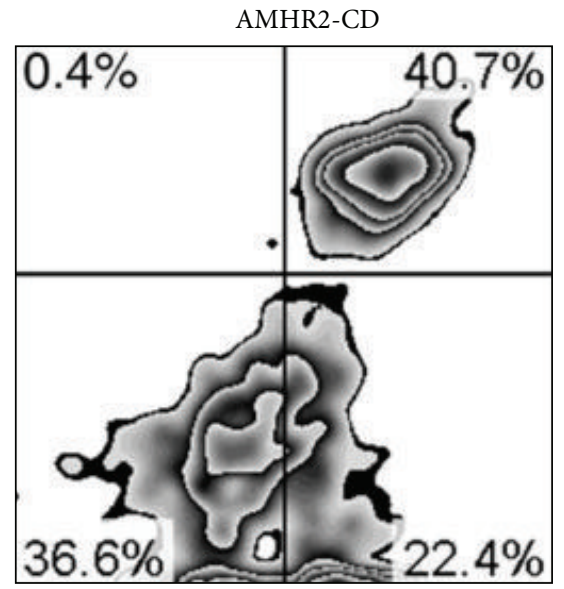

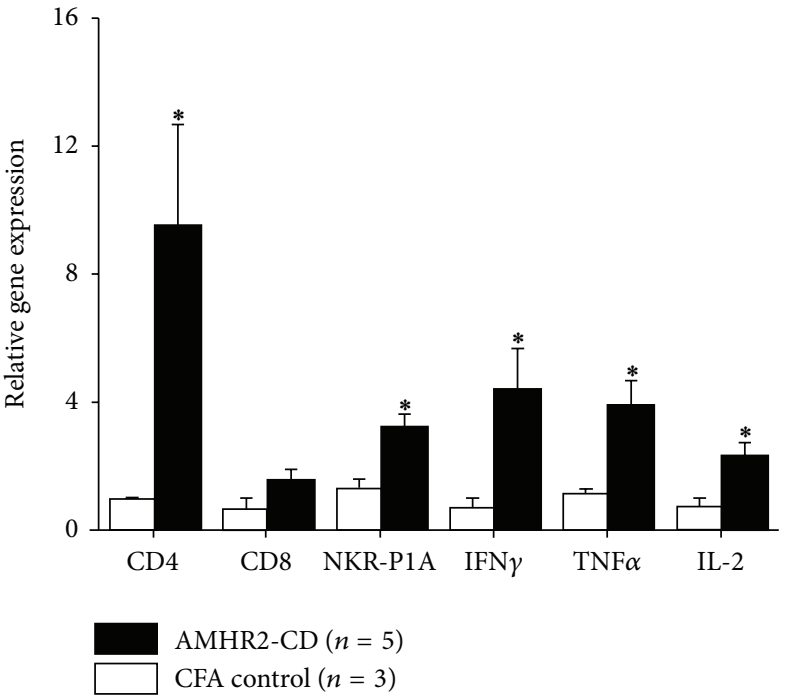

(c)

FIgURE 5: Tumor analysis. (a) Arrows show extensive infiltration of CD3+ T cells in an ID8 tumor from AMHR2-CD vaccinated mice in lower resolution (upper panel) and higher resolution (lower panel) images. Inflammatory infiltrates of CD3+ T cells were never observed in control mice vaccinated with CFA alone. (b) Flow cytometry analysis of TILs gated on the CD3+ T cell population showed a pronounced increase in percentages of CD4+ T cells but not CD8+ T cells in tumor infiltrates from mice vaccinated with AMHR2-CD compared to control mice immunized with CFA alone. Data shown are representative of three experiments yielding similar results. (c) Tumors from AMHR2-CD immunized mice consistently showed increased relative gene expression for CD4, IFN $\gamma$, TNF $\alpha$, NKR-P1A, and IL-2 but not for CD8. Asterisks indicate statistical significance. Error bars show \pm SD. 


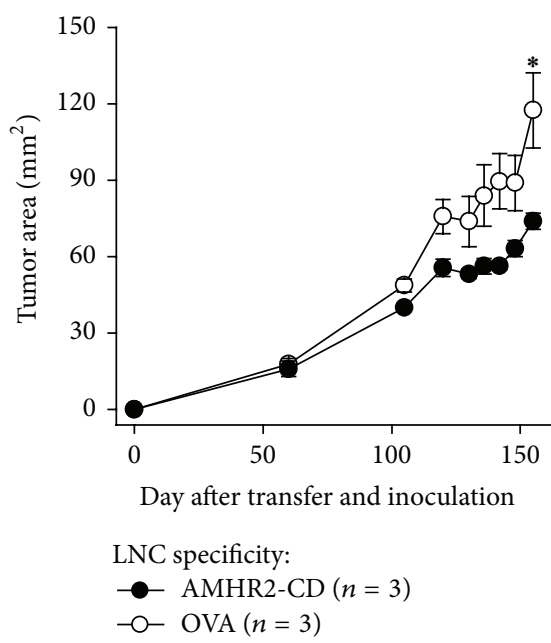

(a)

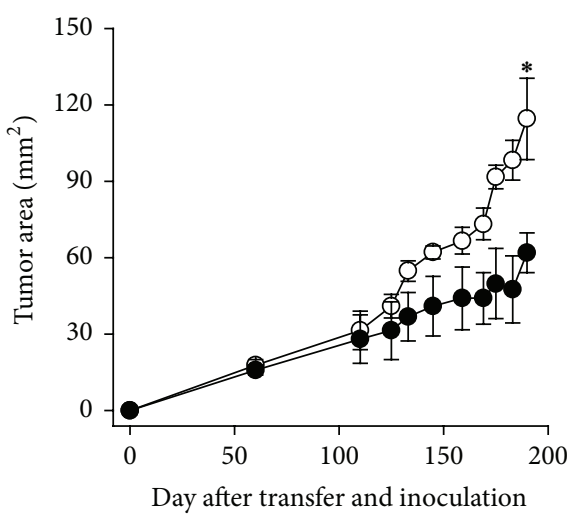

Splenocyte specificity:

$\rightarrow$ AMHR2-CD $(n=4)$ -0 OVA $(n=4)$

(b)

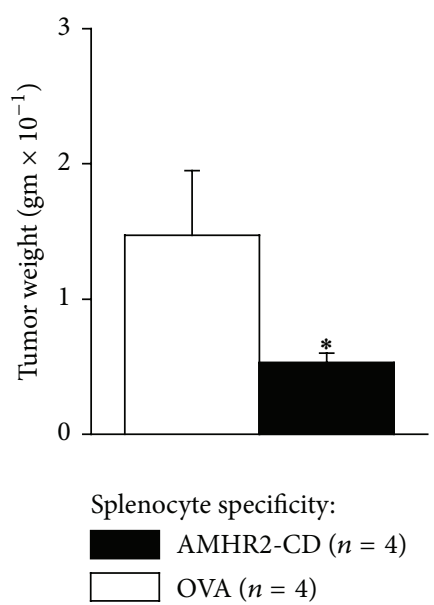

(c)

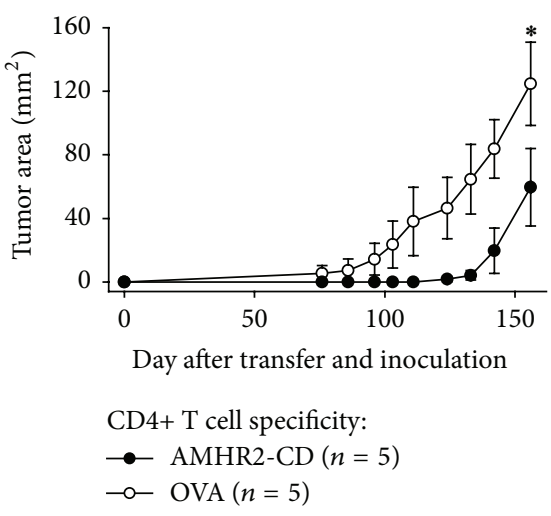

(d)

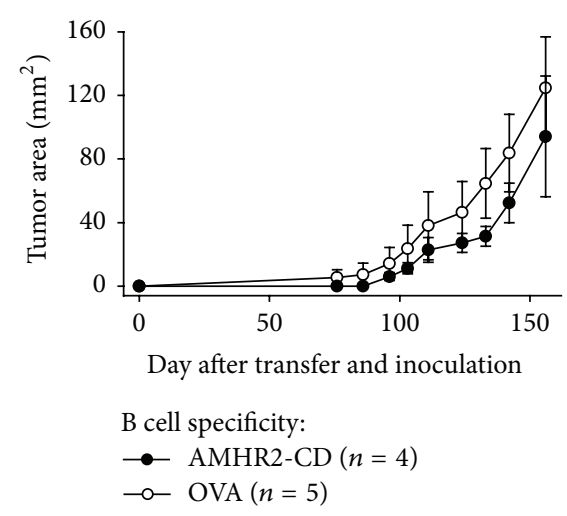

(e)

FIGURE 6: Passive transfer of immune protection against tumor growth with CD4+ T cells. Recipient mice were inoculated with ID8 tumor cells on the day after cell transfer. Growth of ID8 tumors was inhibited in mice transferred with AMHR2-CD-specific (a) LNCs and (b) splenocytes. (c) At 190 days after splenocyte transfer and inoculation, mean tumor weights were lower in recipients of AMHR2-CD-specific splenocytes compared to recipients of OVA-specific splenocytes. Transfer of purified AMHR2-CD-specific (d) CD4+ T cells but not (e) B220+ B cells inhibited ID8 tumor growth. Asterisks indicate statistical significance. Error bars show \pm SE.

protein expressed in the vast majority of human EOCs, provides effective therapy and prophylaxis against ovarian cancer. It is particularly encouraging that the inhibition of tumor growth was accompanied by a mild ovarian inflammation that resolved quickly with no detectable effects on fertility over the course of several subsequent mating cycles. This rather benign autoimmune phenotype was associated with a significant inhibition of tumor growth when vaccination occurred as a therapeutic intervention. It is important to note that the appearance of the therapeutic effect took over five months to clearly manifest as defined by a complete separation of the tumor growth curves (Figure 4(e)), thereby implying that earlier vaccination as a preventive strategy would be even more effective in controlling EOC. Indeed, the highly significant $41.7 \%$ increased OS that occurred when TgMISIIR-TAg mice were vaccinated prophylactically supports this view. However, in light of several reports indicating extraovarian gene and protein expression of AMHR2, the likelihood of using AMHR2-CD vaccination as prophylaxis against EOC seems unlikely.
AMHR2 gene and protein expression have been repeatedly detected in adult motor neurons in mice [29-32], in normal adult rat endometrium, at low levels in the normal rat uterus, and at substantially higher levels in the gravid rat uterus [33]. Although AMHR2 gene expression has also been shown to occur in brain, adrenal, and lung tissues of adult male mice, the detected levels were less than $1 \%$ of those occurring in adult testes, and protein detection was either not reported or not prominent [34]. Similarly, AMHR2 gene expression has been detected in normal rat and normal human breast tissues, but detection of the AMHR2 protein was not reported in either of these tissues [35].

Despite extensive literature on extraovarian gene expression of $A M H R 2$, recent rigorous studies have provided more precise understanding of the subtle but important features involved in $A M H R 2$ gene expression in different normal human tissues. Quantitative estimates of transcript abundance by mRNA sequencing have shown that expression of the full-length AMHR2 transcript is confined to the ovary in adult women whereas alternative splice isoforms 
coding for known truncated AMHR2 proteins as well as several noncoding transcripts are expressed in the cortex and medulla of the adrenal gland and at substantially lower levels in the spleen and exocrine cells of the pancreas [17]. Expression of truncated isoforms of AMHR2 also occurs in human skeletal muscle and heart but at levels, respectively, representing only $4.2 \%$ and $1.5 \%$ of the level expressed in the ovary. Thus, it seems that the extraovarian expression of AMHR2 reported in the literature refers to alternatively spliced transcripts that either code for truncated variant AMHR2 proteins or represent noncoding transcripts with no open reading frames $[16,17]$. Noncoding AMHR2 transcripts have been shown to play a role in regulating AMHR2mediated signaling [34] whereas all of the truncated AMHR2 transcripts with open reading frames have substantial deletions in the cytoplasmic domain of AMHR2 and as such are not capable of translating the complete AMHR2-CD sequence $[16,17]$. Thus, the substantial AMHR2 deletions in nonovarian tissues may preclude the development of any life-threatening peripheral autoimmunity as evidenced by the lack of any observed extraovarian autoimmunity in our AMHR2-CD vaccinated mice and by the dramatically increased OS occurring in female TgMISIIR-TAg transgenic mice vaccinated prophylactically against AMHR2-CD.

The lack of any observed nonovarian autoimmunity in females provides several noteworthy considerations when selecting cancer vaccine targets including the importance of recognizing differences between immunogenic and nonimmunogenic tissue expression levels when anticipating autoimmune consequences of cancer vaccination. In addition, one must evaluate the significance of species-specific differences in tissue expression of cancer vaccine targets, since, unlike the mouse [35], AMHR2 transcripts have not been detected in any of the normal human brain tissues examined [17]. In any event, extraovarian expression of AMHR2 transcripts does little to diminish the usefulness of AMHR2-CD as an immune target for immunotherapy of EOC particularly in light of the urgent need to improve the poor prognosis of women diagnosed with EOC and the unusually high immunogenicity of AMHR2-CD indicated by $\mathrm{T}$ cell production of high levels of IFN $\gamma$ and induction of extremely high serum antibody titers with prominent detection of AMHR2-CD-specific IgG occurring even at serum dilutions exceeding 1:50,000 (Figure 2(f)).

It is notable that a single immunization with AMHR2$\mathrm{CD}$ is capable of inducing sufficient tumor immunity without eliciting a detectable CD8 T cell response. Although immunization with tissue-specific self-proteins often fails to elicit CD8 $\mathrm{T}$ cell responses, it may be presumptuous to conclude that such failure is due to the single immunization protocol. Indeed, we have previously shown that $\mathrm{CD} 4$ and $\mathrm{CD} 8 \mathrm{~T}$ cell responses occur following single immunizations with $\alpha$-lactalbumin and uroplakin II for effective induction of autoimmune breast failure and interstitial cystitis, respectively $[26,36]$. In fact, booster immunizations often diminish effective immunity [37]. Thus, failure to induce CD8 T cell responses cannot be explained simply by inadequate priming and may instead be due to the unavailability of autoreactive CD8 $\mathrm{T}$ cells capable of responding to a specific self-protein possibly as a result of a more efficient thymic deletion of the high affinity CD8 T cell repertoire. In such cases, booster immunizations would simply recruit low affinity $\mathrm{T}$ cell clones representing a nondominant or cryptic $\mathrm{T}$ cell repertoire capable of limited clinical impact. Although optimal tumoricidal activity may typically occur when tumor responses involve both CD4 and CD8 T cells [38], CD4 T cells by themselves can provide powerful tumor immunity often exceeding that provided by $\mathrm{CD} 8 \mathrm{~T}$ cells even when tumors fail to express major histocompatibility complex (MHC) class II molecules [39]. Studies to determine the basis for the unusually high immunogenicity of AMHR2-CD are ongoing.

A variety of mechanisms may contribute to CD4mediated tumor immunity including induction of help for tumor responsive $\mathrm{CD} 8+\mathrm{T}$ cell responses, induction of tumor cytotoxicity, upregulation of expression of MHC molecules for enhancing recognition of tumor antigens, inhibition of angiogenesis, and induction of tumor dormancy (reviewed in [40]). Most of these mechanisms are directly or indirectly related to upregulation of IFN $\gamma$ and TNF $\alpha$ gene expression both of which occurred in tumors from mice vaccinated against AMHR2-CD (Figure 5(c)). Moreover, enhanced gene expression for the natural killer cell receptor, NKRP1A, in tumors from mice vaccinated against AMHR2-CD (Figure 5(c)), implies that NK cells may also play a role in the observed tumor immunity perhaps as a result of recruitment through IFN $\gamma$-dependent CXCR3 signaling [41] or through an IL-17/CCL2 recruitment mechanism [42]. Thus, CD4+ T cells may also mediate upregulated expression of angiostatic chemokines such as CXCL9, CXCL10, and CXCL14 that are capable of inhibiting tumor growth (reviewed in [40]) or may downregulate expression of the chemokine receptor CXCR2 or its many ligands that promote angiogenesis (reviewed in $[43,44])$. Studies are currently underway to distinguish the underlying mechanism(s) involved in the therapeutic efficacy of AMHR2-CD vaccination against EOC.

\section{Conclusion}

In several mouse models of EOC, a single vaccination against AMHR2-CD is sufficient to provide effective immune control over the growth of ovarian tumors. Notably, this vaccineinduced tumor immunity occurs in the absence of any severe autoimmune consequences. Thus, AMHR2 vaccination may be useful in controlling the more malignant forms of human ovarian cancer.

\section{Abbreviations}

AMH:

AMHR2:

AMHR2-CD:

AIRE:

CA-125:

CTAG1B or NY-ESO-1: Cancer-testis antigen 1

CFA:
Anti-Müllerian hormone Anti-Müllerian hormone receptor 2

Anti-Müllerian hormone receptor, type II-cytoplasmic domain Autoimmune regulator transcription factor Cancer antigen 25 Complete Freund's adjuvant 


$\begin{array}{ll}\text { cpm: } & \text { Counts per minute } \\ \text { DC: } & \text { Dendritic cell } \\ \text { EOC: } & \text { Epithelial ovarian cancer } \\ \text { HPLC: } & \text { High performance liquid chromatography } \\ \text { HRP: } & \text { Horse radish peroxidase } \\ \text { HER2/neu: } & \text { Human epidermal growth factor receptor } \\ & \text { tyrosine kinase } \\ \text { IFN } \gamma: & \text { Interferon gamma } \\ \text { IPTG: } & \text { Isopropyl } \beta \text {-D-1-thiogalactopyranoside } \\ \text { NKR-P1A: } & \text { Natural killer cell lectin-like receptor } \\ & \text { subfamily B, member 1 } \\ \text { LNC: } & \text { Lymph node cells } \\ \text { MHC: } & \text { Major histocompatibility complex } \\ \text { mTECs: } & \text { Medullary thymic epithelial cells } \\ \text { MOSEC: } & \text { Mouse ovarian surface epithelial cells } \\ \text { Ni-NTA: } & \text { Nickel-nitrilotriacetic acid } \\ \text { NK: } & \text { Natural killer } \\ \text { OS: } & \text { Overall survival } \\ \text { OVA: } & \text { Ovalbumin } \\ \text { qRT-PCR: } & \text { Quantitative real-time RT-PCR } \\ \text { SV40-Tag: } & \text { Simian virus } 40 \text { large T antigen } \\ \text { TCR: } & \text { T cell receptor } \\ \text { TGF } \beta: & \text { Transforming growth factor } \beta \\ \text { TILs: } & \text { Tumor infiltrating lymphocytes } \\ \text { TAA: } & \text { Tumor associated antigen } \\ \text { TNF } \alpha: & \text { Tumor necrosis factor alpha. } \\ & \end{array}$

\section{Conflict of Interests}

This work was supported by a grant from Shield Biotech, Inc., Cleveland, $\mathrm{OH}$, as privately owned company. Vincent $\mathrm{K}$. Tuohy is the primary inventor of vaccines that have been licensed to Shield Biotech, Inc., and is the Chief Science Officer of Shield Biotech, Inc. As such, Vincent K. Tuohy may in the future receive commercialization revenues for these technologies. All other authors declare that there is no conflict of interests.

\section{Authors' Contribution}

Cagri Sakalar, Suparna Mazumder, Cengiz Z. Altuntas, Justin M. Johnson, Robert Aguilar, Sathyamangla V. Naga Prasad, and Vincent K. Tuohy were involved in the development of methodology and in the acquisition of data. Cagri Sakalar, Suparna Mazumder, Ritika Jaini, Denise C. Connolly, and Vincent K. Tuohy were involved in the analysis and interpretation of the data. Cagri Sakalar, Suparna Mazumder, Denise C. Connolly, and Vincent K. Tuohy participated in the writing, review, and revision of the paper. Vincent K. Tuohy was instrumental in the conception, experimental design, and overall supervision of the project.

\section{Acknowledgments}

The authors express their gratitude to Dr. Kathy Roby, University of Kansas Medical Center, Kansas City, KS, for generously providing the murine ID8 EOC cell line. The authors also wish to thank Elizabeth E. Martelli, Department of Molecular Cardiology, Lerner Research Institute, Cleveland Clinic, Cleveland, $\mathrm{OH}$, for providing expert assistance with in vivo imaging of ovarian tumors.

\section{References}

[1] G. F. Fleming, B. M. Ronnett, J. Seidman, R. J. Zaino, and S. C. Rubin, "Epithelial ovarian cancer," in Principles and Practice of Gynecologic Oncology, R. R. Barakat, M. Markman, and M. E. Randall, Eds., pp. 763-835, Lippincott Williams and Wilkins, Philadelphia, Pa, USA, 5th edition, 2009.

[2] R. Siegel, J. Ma, Z. Zou, and A. Jemal, "Cancer statistics, 2014," CA: A Cancer Journal for Clinicians, vol. 64, no. 1, pp. 9-29, 2014.

[3] N. Howlader, A. M. Noone, M. Krapcho et al., Eds., SEER Cancer Statistics Review, 1975-2012, National Cancer Institute, Bethesda, Md, USA, 2014, http://seer.cancer.gov/csr/1975_2012/.

[4] L. Zhang, J. R. Conejo-Garcia, D. Katsaros et al., "Intratumoral T cells, recurrence, and survival in epithelial ovarian cancer," The New England Journal of Medicine, vol. 348, no. 3, pp. 203213, 2003.

[5] L. E. Kandalaft, D. J. Powell Jr., N. Singh, and G. Coukos, "Immunotherapy for ovarian cancer: what's next?" Journal of Clinical Oncology, vol. 29, no. 7, pp. 925-933, 2011.

[6] M. A. Bookman, K. M. Darcy, D. Clarke-Pearson, R. A. Boothby, and I. R. Horowitz, "Evaluation of monoclonal humanized anti-HER2 antibody, trastuzumab, in patients with recurrent or refractory ovarian or primary peritoneal carcinoma with overexpression of HER2: a phase II trial of the Gynecologic Oncology Group," Journal of Clinical Oncology, vol. 21, no. 2, pp. 283-290, 2003.

[7] K. Odunsi, A. A. Jungbluth, E. Stockert et al., "NY-ESO-1 and LAGE-1 cancer-testis antigens are potential targets for immunotherapy in epithelial ovarian cancer," Cancer Research, vol. 63, no. 18, pp. 6076-6083, 2003.

[8] D. G. Rosen, L. Wang, J. N. Atkinson et al., "Potential markers that complement expression of CA125 in epithelial ovarian cancer," Gynecologic Oncology, vol. 99, no. 2, pp. 267-277, 2005.

[9] M. E. Dudley, J. R. Wunderlich, P. F. Robbins et al., "Cancer regression and autoimmunity in patients after clonal repopulation with antitumor lymphocytes," Science, vol. 298, no. 5594, pp. 850-854, 2002.

[10] F. S. Hodi, S. J. O’Day, D. F. McDermott et al., "Improved survival with ipilimumab in patients with metastatic melanoma," The New England Journal of Medicine, vol. 363, no. 8, pp. 711723, 2010.

[11] P. W. Kantoff, C. S. Higano, N. D. Shore et al., "Sipuleucel$\mathrm{T}$ immunotherapy for castration-resistant prostate cancer," The New England Journal of Medicine, vol. 363, no. 5, pp. 411-422, 2010.

[12] P. T. Masiakos, D. T. MacLaughlin, S. Maheswaran et al., "Human ovarian cancer, cell lines, and primary ascites cells express the human Mullerian inhibiting substance (MIS) type II receptor, bind, and are responsive to MIS," Clinical Cancer Research, vol. 5, no. 11, pp. 3488-3499, 1999.

[13] J. N. Bakkum-Gamez, G. Aletti, K. A. Lewis et al., "Müllerian inhibiting substance type II receptor (MISIIR): a novel, tissuespecific target expressed by gynecologic cancers," Gynecologic Oncology, vol. 108, no. 1, pp. 141-148, 2008.

[14] J. Y. Song, K. Y. Chen, S. Y. Kim et al., "The expression of Müllerian inhibiting substance/anti-Müllerian hormone type II receptor protein and mRNA in benign, borderline and 
malignant ovarian neoplasia," International Journal of Oncology, vol. 34, no. 6, pp. 1583-1591, 2009.

[15] N. Josso, N. Di Clemente, and L. Gouédard, "Anti-Müllerian hormone and its receptors," Molecular and Cellular Endocrinology, vol. 179, no. 1-2, pp. 25-32, 2001.

[16] E. Faure, L. Gouédard, S. Imbeaud et al., "Mutant isoforms of the anti-Müllerian hormone type II receptor are not expressed at the cell membrane," The Journal of Biological Chemistry, vol. 271, no. 48, pp. 30571-30575, 1996.

[17] M. Uhlén, L. Fagerberg, B. M. Hallström et al., "Proteomics. Tissue-based map of the human proteome," Science, vol. 347, no. 6220, Article ID 1260419, 2015.

[18] W. M. Baarends, M. J. L. van Helmond, M. Post et al., "A novel member of the transmembrane serine/threonine kinase receptor family is specifically expressed in the gonads and in mesenchymal cells adjacent to the müllerian duct," Development, vol. 120, no. 1, pp. 189-197, 1994.

[19] A. L. L. Durlinger, J. A. Visser, and A. P. N. Themmen, "Regulation of ovarian function: the role of anti-Müllerian hormone," Reproduction, vol. 124, no. 5, pp. 601-609, 2002.

[20] D. T. MacLaughlin and P. K. Donahoe, "Mullerian inhibiting substance: an update," Advances in Experimental Medicine and Biology, vol. 511, pp. 25-38, 2002.

[21] K. F. Roby, C. C. Taylor, J. P. Sweetwood et al., "Development of a syngeneic mouse model for events related to ovarian cancer," Carcinogenesis, vol. 21, no. 4, pp. 585-591, 2000.

[22] D. C. Connolly, R. Bao, A. Y. Nikitin et al., "Female mice chimeric for expression of the simian virus $40 \mathrm{TAg}$ under control of the MISIIR promoter develop epithelial ovarian cancer," Cancer Research, vol. 63, no. 6, pp. 1389-1397, 2003.

[23] Y. Mishina, R. Tizard, J. M. Deng et al., "Sequence, genomic organization, and chromosomal location of the mouse Müllerian-inhibiting substance type II receptor gene," Biochemical and Biophysical Research Communications, vol. 237, no. 3, pp. 741-746, 1997.

[24] A. Dudley, W. McKinstry, D. Thomas, J. Best, and A. Jenkins, "Removal of endotoxin by reverse phase HPLC abolishes antiendothelial cell activity of bacterially expressed plasminogen kringle 5," BioTechniques, vol. 35, no. 4, pp. 724-730, 2003.

[25] D. Zippel, A. Shalmon, A. Rundstein et al., "Freehand elastography for determination of breast cancer size: comparison with Bmode sonography and histopathologic measurement," Journal of Ultrasound in Medicine, vol. 33, no. 8, pp. 1441-1446, 2014.

[26] P. Kesaraju, R. Jaini, J. M. Johnson et al., "Experimental autoimmune breast failure: a model for lactation insufficiency, postnatal nutritional deprivation, and prophylactic breast cancer vaccination," The American Journal of Pathology, vol. 181, no. 3, pp. 775-784, 2012.

[27] M.-J. Baek, H.-M. Park, J. M. Johnson et al., "Increased frequencies of cochin-specific T cells in patients with autoimmune sensorineural hearing loss," Journal of Immunology, vol. 177, no. 6, pp. 4203-4210, 2006.

[28] J. C. Ryan, E. C. Niemi, M. C. Nakamura, and W. E. Seaman, "NKR-P1A is a target-specific receptor that activates natural killer cell cytotoxicity," Journal of Experimental Medicine, vol. 181, no. 5, pp. 1911-1915, 1995.

[29] A. N. Clarkson, C. L. Talbot, P.-Y. Wang, D. T. MacLaughlin, P. K. Donahoe, and I. S. McLennan, "Müllerian inhibiting substance is anterogradely transported and does not attenuate avulsion-induced death of hypoglossal motor neurons," Experimental Neurology, vol. 231, no. 2, pp. 304-308, 2011.
[30] N. Lebeurrier, S. Launay, R. Macrez et al., "Anti-Müllerianhormone-dependent regulation of the brain serine-protease inhibitor neuroserpin," Journal of Cell Science, vol. 121, part 20, pp. 3357-3365, 2008.

[31] P.-Y. Wang, K. Koishi, A. B. McGeachie et al., "Mullerian Inhibiting Substance acts as a motor neuron survival factor in vitro," Proceedings of the National Academy of Sciences of the United States of America, vol. 102, no. 45, pp. 16421-16425, 2005.

[32] P.-Y. Wang, A. Protheroe, A. N. Clarkson, F. Imhoff, K. Koishi, and I. S. McLennan, "Müllerian inhibiting substance contributes to sex-linked biases in the brain and behavior," Proceedings of the National Academy of Sciences of the United States of America, vol. 106, no. 17, pp. 7203-7208, 2009.

[33] E. J. Renaud, D. T. MacLaughlin, E. Oliva, B. R. Rueda, and P. K. Donahoe, "Endometrial cancer is a receptor-mediated target for Mullerian Inhibiting Substance," Proceedings of the National Academy of Sciences of the United States of America, vol. 102, no. 1, pp. 111-116, 2005.

[34] F. M. Imhoff, D. Yang, S. F. Mathew et al., "The type 2 anti-Müllerian hormone receptor has splice variants that are dominant-negative inhibitors," FEBS Letters, vol. 587, no. 12, pp. 1749-1753, 2013.

[35] D. L. Segev, T. U. Ha, T. T. Tran et al., "Mullerian inhibiting substance inhibits breast cancer cell growth through an $\mathrm{NF} \kappa \mathrm{B}$ mediated pathway," Journal of Biological Chemistry, vol. 275, no. 37, pp. 28371-28379, 2000.

[36] C. Z. Altuntas, F. Daneshgari, C. Sakalar et al., "Autoimmunity to uroplakin II causes cystitis in mice: a novel model of interstitial cystitis," European Urology, vol. 61, no. 1, pp. 193-200, 2012.

[37] S. E. Church, S. M. Jensen, C. G. Twitty et al., "Multiple vaccinations: friend or foe," Cancer Journal, vol. 17, no. 5, pp. 379-396, 2011.

[38] A. L. Marzo, R. A. Lake, B. W. S. Robinson, and B. Scott, “T-cell receptor transgenic analysis of tumor-specific CD8 and CD4 responses in the eradication of solid tumors," Cancer Research, vol. 59, no. 5, pp. 1071-1079, 1999.

[39] A. Perez-Diez, N. T. Joncker, K. Choi et al., "CD4 cells can be more efficient at tumor rejection than CD8 cells," Blood, vol. 109, no. 12, pp. 5346-5354, 2007.

[40] Y. P. Lai, C. J. Jeng, and S. C. Chen, "The roles of CD4 ${ }^{+}$T cells in tumor immunity," ISRN Immunology, vol. 2011, Article ID 497397, 6 pages, 2011.

[41] M. A. Pak-Wittel, L. Yang, D. K. Sojka, J. G. Rivenbark, and W. M. Yokoyama, "Interferon- $\gamma$ mediates chemokine-dependent recruitment of natural killer cells during viral infection," Proceedings of the National Academy of Sciences of the United States of America, vol. 110, no. 1, pp. E50-E59, 2013.

[42] R. Saddawi-Konefka, T. O’Sullivan, E. T. Gross, A. Washington Jr., and J. D. Bui, “Tumor-expressed IL-17D recruits NK cells to reject tumors," Oncoimmunology, vol. 3, no. 12, Article ID e954853, 2015.

[43] D. Raman, P. J. Baugher, Y. M. Thu, and A. Richmond, "Role of chemokines in tumor growth," Cancer Letters, vol. 256, no. 2, pp. 137-165, 2007.

[44] M. Santoni, S. Bracarda, M. Nabissi et al., "CXC and CC chemokines as angiogenic modulators in nonhaematological tumors," BioMed Research International, vol. 2014, Article ID 768758, 12 pages, 2014. 


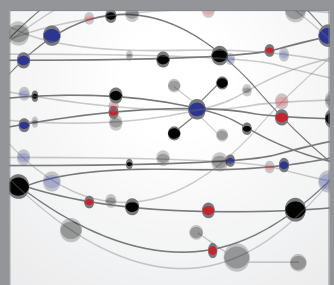

The Scientific World Journal
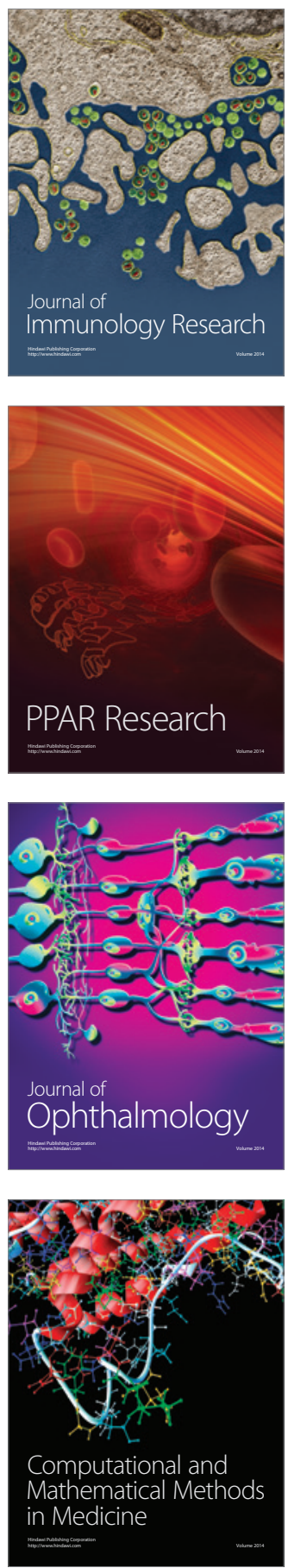

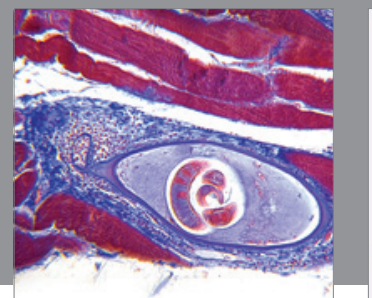

Gastroenterology

Research and Practice
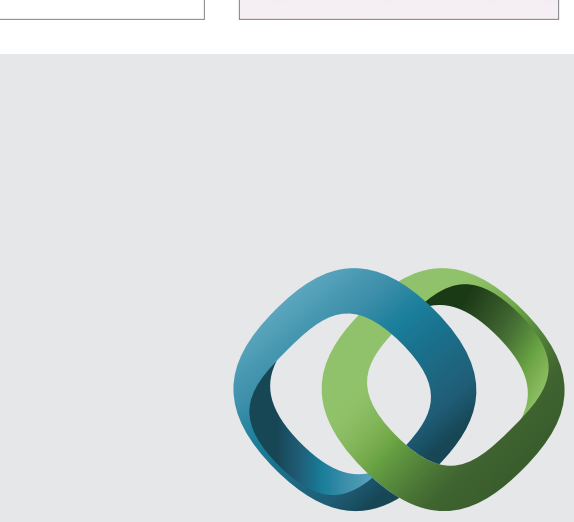

\section{Hindawi}

Submit your manuscripts at

http://www.hindawi.com
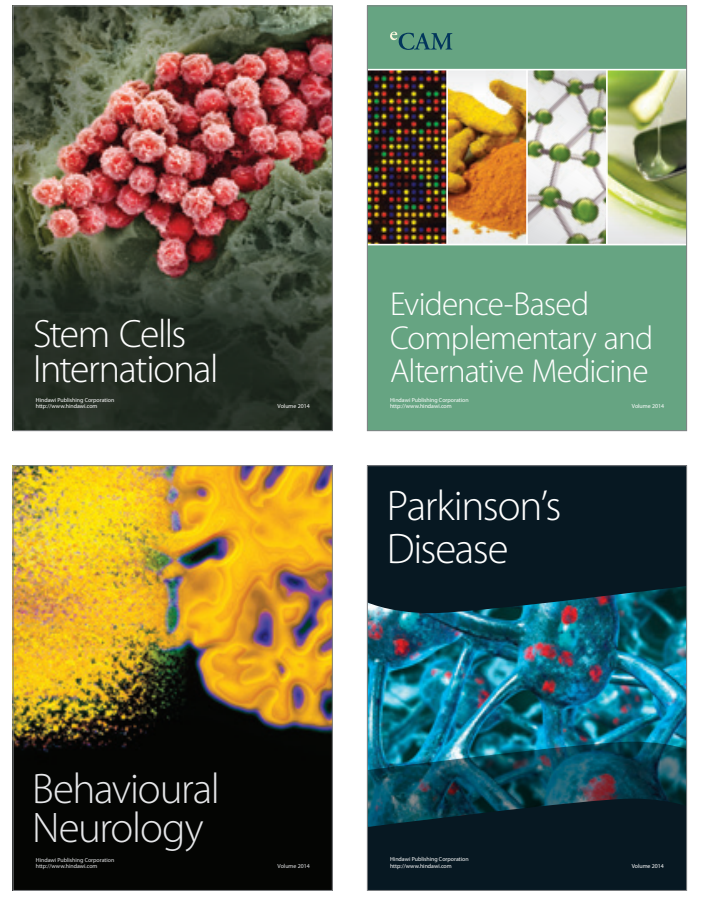
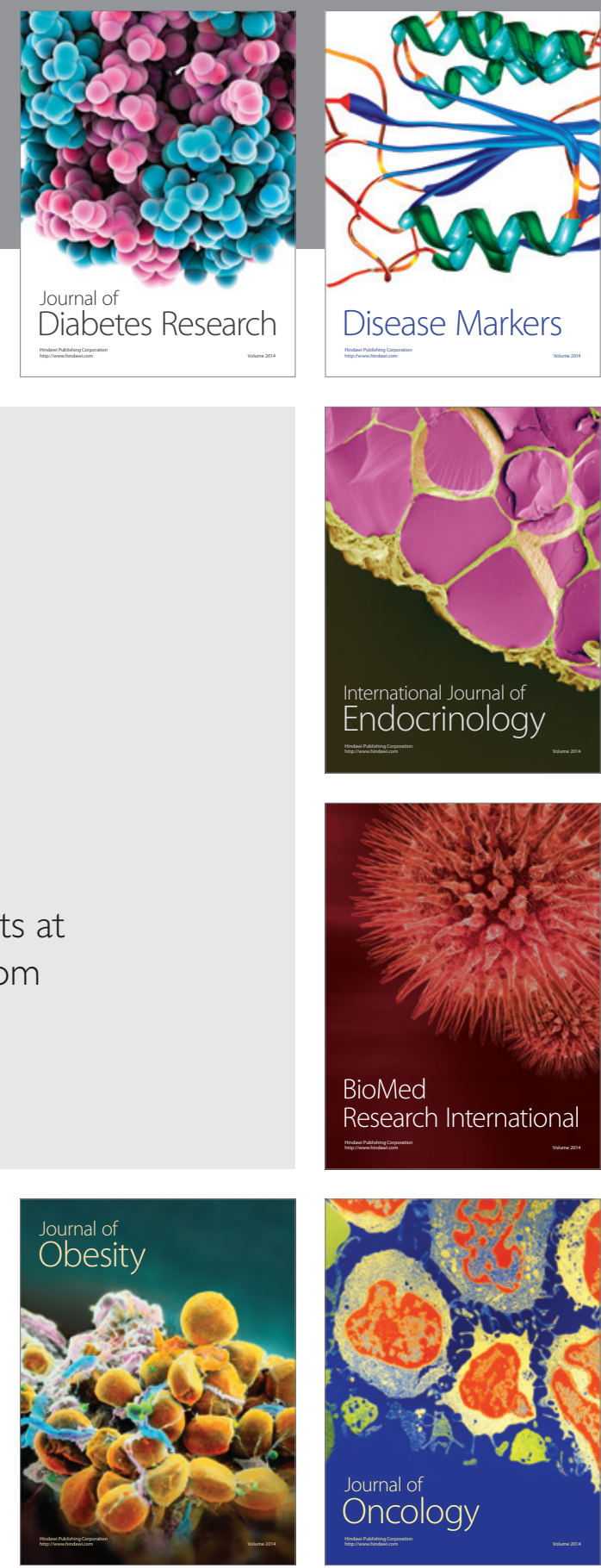

Disease Markers
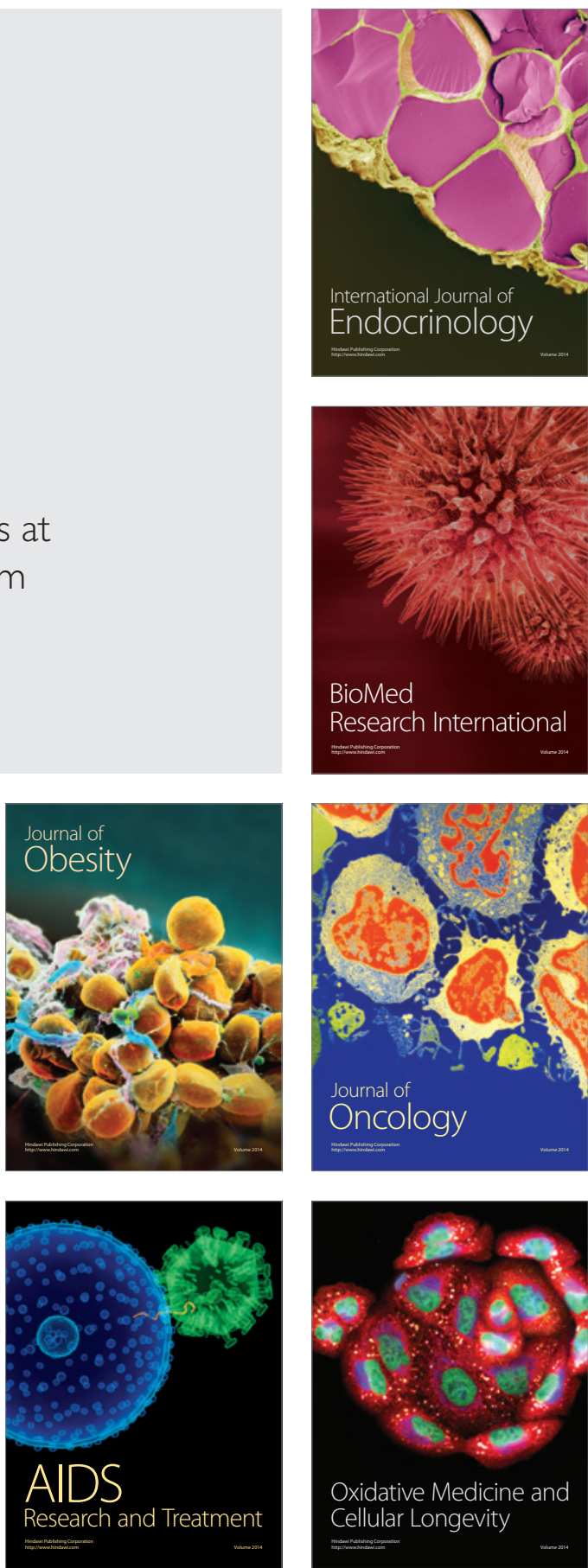